\title{
Autorschaft und Autorisierungsstrategien in apokalyptischen Texten
}

\author{
Hrsg. v. Jörg Frey, Michael R. Jost, Franz Tóth, unter Mitwirkung v. Johannes \\ Stettner
}

Autorschaft und Autorisierungsstrategien in apokalyptischen Texten

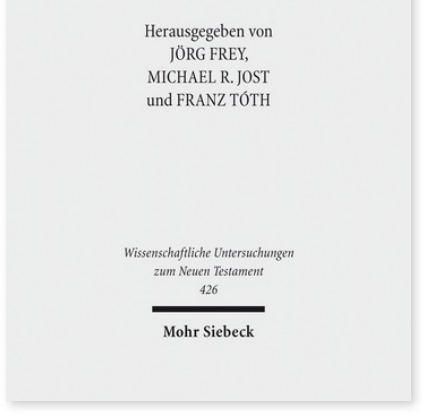

2019. XII, 462 Seiten. WUNT I 426

ISBN 978-3-16-157024-7

Leinen $174,00 €$

ISBN 978-3-16-157025-4

eBook PDF $174,00 €$
Der Band bietet eine breite Analyse und Reflexion der Autorschaftskonzepte und Autorisierungsstrategien in frühjüdischen und frühchristlichen apokalyptischen Texten. Dabei wird zunächst grundlegend nach der Bedeutung von Autorschaft und Autorisierungskonzepten in der Literaturwissenschaft gefragt, und die breite Vielfalt an Vorstellungen von Autorschaft in der griechisch-römischen Antike erhoben. Einzelbeiträge analysieren die Konstruktion von Autorschaft von den biblischen Prophetenbüchern über die Anfänge der jüdischen Apokalyptik in der Henochliteratur und im Danielbuch, das 4. Esra- und das 2. Baruchbuch und die Jakobsleiter bis in die rabbinische Literatur. Ein zweiter Hauptteil erörtert die Phänomene der Autorisierung und Autorschaftskonstruktion in christlichen Apokalypsen von der Johannesapokalypse und der Petrusapokalypse bis zur lateinischen Paulusapokalypse. Eine rezeptionsgeschichtliche Studie zur späten Nachwirkung der Apokalyptik in Dantes Göttlicher Komödie schließt den Band ab.

\section{Inhaltsübersicht}

\section{Einführung und Allgemeines}

Franz Tóth: Autorschaft und Autorisation - Martina Janßen: »Was ist ein Autor?« Vorstellungen und (Selbst-)Inszenierungen von Autorschaft in der Antike

\section{Frühjüdische Literatur}

Konrad Schmid: How the Prophets Became Biblical Authors and How the Biblical Authors Became Prophets - John J. Collins: Torah and Higher Revelation in the Jewish Apocalypses - Matthew Goff: Reading Jewish Wisdom From Before the Flood: Authorship, Prophecy, and Textuality in Enochic Literature - Stefan Krauter: Warum Esra? Beobachtungen zum Autorkonzept des. 4. Esrabuches - István Czachesz: Visions with Authority. Reconsidering the Origins and Transmission of Apocalyptic Visions, with Special Attention to Jewish and Christian Pseudepigrapha - Jordash Kiffiak: Pseudonymity in 2 Baruch: Jeremiah 45.1-5 as the Fertile Seedbed for a Hopeful Exhortation - Christfried Böttrich: Der Stammvater als Offenbarungsträger. Autorisationsstrategien in der apokryphen Leiter Jakobs - Michae/ Tilly: Apokalyptik und Mystik im rabbinischen Judentum

\section{Frühchristliche Literatur}

Adela Yarbro Collins: The Construction of the Author's Authority in the Book of Revelation as a Whole - Jan Dochhorn: Zur Konstruktion von Autorschaft in der Ascensio Jesaiae - Tobias Nicklas: Petrusoffenbarung, Christusoffenbarung und ihre Funktion: Autoritätskonstruktion in der Petrusapokalypse - Thomas J. Kraus: »Wieviel 'Paulus' ist in der Apokalypse des Paulus/Visio Pauli?"Eine Apokalypse und ihr Protagonist

\section{Zur Nachwirkung der Antike}

Gerhard Regn: Die Apokalypse im Irdischen Paradies. Offenbarung, Allegorie und Dichtung in Dantes Commedia

Jörg Frey Geboren 1962; 1996 Promotion; 1998 Habilitation; Professur für neutestamentliche Wissenschaft mit den Schwerpunkten Antikes Judentum und Hermeneutik an der Theologischen Fakultät der Universität Zürich und Research Associate der University of the Free State, Bloemfontein/ZA. https://orcid.org/0000-0001-6628-8834

Michael R. Jost Geboren 1982; 2018 Promotion; derzeit Postdoc an der Theologischen Fakultät der Universität Zürich, Assistent an der Theologischen Fakultät der Universität Bern und seit 2021 Research Associate der University of Pretoria, Südafrika.

https://orcid.org/0000-0001-6140-5624

Franz Tóth Geboren 1972; 1993-99 Studium der Philosophie und Theologie; 2005 Promotion; 2014 Habilitation; 2015 Lehrstuhlvertretung für Prof. Dr. Matthias Konradt an der Ruprecht-Karls-Universität Heidelberg; seit 2017 Privatdozent an der Theologischen Fakultät der Universität Zürich.

Johannes Stettner Geboren 1988; Studium von Latein und Kath. Theologie (Lehramt Gymnasium) an der Universität Regensburg; 2013 Erstes Staatsexamen; 2017 Promotion; 2019 Zweites Staatsexamen; seit September 2019 Studienrat am Anne-Frank-Gymnasium Erding.

Jetzt bestellen:

https://www.mohrsiebeck.com/buch/autorschaft-und-autorisierungsstrategien-in-apokalyptischen-texten-9783161570247? no_cache=1

order@mohrsiebeck.com

Telefon: +49 (0)7071-923-17 
Telefax: +49 (0)7071-51104

Mohr Siebeck GmbH \& Co. KG

Postfach 2040

D-72010 Tübingen

info@mohrsiebeck.com

Mohr Siebeck

www.mohrsiebeck.com 